\title{
Application of Statistical Energy Analysis (SEA) in Estimating Acoustic Response of Panels With Non- Uniform Mass Distribution
}

\author{
K. Renji \\ Advanced Technology Development Group, UR Rao Satellite Center, ISRO Vimanapura Post, Bangalore, India \\ 560017.
}

(Received 20 September 2020; accepted 18 December 2020)

Statistical Energy Analysis (SEA) is generally used in estimating the responses of structures to high frequency acoustic excitation. Though it has been successfully applied for panels having uniform mass, its usage is limited when the mass distribution is not uniform, as seen in equipment panels of a spacecraft. Results for such panels are seldom reported. In this work, an attempt is made to address this gap. A methodology to estimate the responses of such panels in SEA framework is presented and demonstrated for an equipment panel of a spacecraft, thus widening its application. This is accomplished through SEA along with the information on the standing waves generated due to the change in the structural properties. The acceleration responses of a typical equipment panel when subjected to a diffused acoustic field in a reverberation chamber are measured. The responses of the same panel are theoretically estimated using the methodology presented and a reasonably good prediction is seen.

\section{NOMENCLATURE}

\begin{tabular}{|c|c|}
\hline$<a^{2}>$ & $\begin{array}{c}\text { mean square value } \\
\text { of acceleration }\end{array}$ \\
\hline$A$ & area of the plate \\
\hline$A_{i}$ & area of the $i^{t h}$ subsystem \\
\hline$c$ & speed of sound in air \\
\hline$c_{b, i}$ & $\begin{array}{l}\text { speed of the bending wave } \\
\text { in } i^{t h} \text { subsystem }\end{array}$ \\
\hline$D$ & flexural rigidity of the plate \\
\hline$D_{i}$ & flexural rigidity of $i^{t h}$ subsystem \\
\hline$f$ & frequency in $\mathrm{Hz}$ \\
\hline$f_{c}$ & critical frequency in $\mathrm{Hz}$ \\
\hline$k$ & wavenumber \\
\hline$L$ & length of the line junction \\
\hline$n(f)$ & number of modes per $\mathrm{Hz}$ at frequency $f$ \\
\hline$n_{i}$ & modal density of $i^{t h}$ subsystem \\
\hline$N$ & shear rigidity of the panel \\
\hline$p_{r m s}^{2}$ & mean square value of pressure \\
\hline$S$ & $\begin{array}{c}\text { surface area } \\
\text { of the reverberation chamber }\end{array}$ \\
\hline$<v^{2}>$ & mean square value of velocity \\
\hline$<v^{2}>_{x}$ & $\begin{array}{c}\text { spatial average of } \\
\text { mean square value of velocity }\end{array}$ \\
\hline$V$ & volume of the reverberation chamber \\
\hline$V_{i}$ & volume of $i^{t h}$ subsystem \\
\hline $\bar{a}$ & $\begin{array}{l}\text { total sound power absorption coefficient } \\
\text { of the chamber }\end{array}$ \\
\hline$\delta N$ & number of modes in the band \\
\hline$\Delta$ & half-power bandwidth \\
\hline$\eta_{i}$ & $\begin{array}{c}\text { dissipation loss factor of } i^{t h} \text { subsystem } \\
\text { coupling loss factor }\end{array}$ \\
\hline$\eta_{i j}$ & of $i^{t h}$ subsystem to $j^{t h}$ subsystem \\
\hline$\phi_{a a}(f)$ & spectral density of acceleration \\
\hline$\omega$ & circular frequency in $\mathrm{rad} / \mathrm{s}$ \\
\hline
\end{tabular}

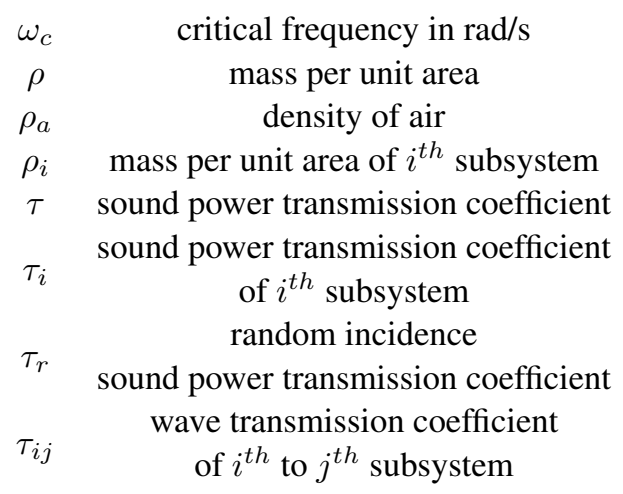

\section{INTRODUCTION}

The structure of a spacecraft consists of several panels connected to each other and several pieces of electronic equipment are mounted on them. During the ascent phase, spacecraft experience high frequency and high intensity acoustic excitations. Information on the vibration responses caused by these acoustic excitations are essential for the design of the structure as well as arriving at suitable random vibration loads for the equipment mounted on them.

Responses of multimodal systems in their higher order modes are generally estimated using Statistical Energy Analysis (SEA). ${ }^{1,2}$ SEA has been successfully used in several applications such as in predicting the response of spacecraft to acoustic excitation, ${ }^{3,4}$ in determining the interior noise in an aircraft, ${ }^{5}$ the responses of VULCAIN engine of Ariane $5^{6}$ etc. Statistical Energy Analysis is a powerful as well as convenient tool in solving vibro-acoustic problems in automobiles. $^{7-9}$ SEA plays a significant role in the vibro-acoustic design of ships, ${ }^{10}$ buildings ${ }^{11,12}$ and high speed trains. ${ }^{13,14}$ Thus one can see that SEA is being used in determining dynamic responses in a wide range of applications, with its known limitations. $^{15,16}$ 
In SEA, the system is comprised of several interacting subsystems. The response estimated for a subsystem is the spatial average over the subsystem and the response at a particular location of the subsystem is not estimated. Other than the spatial average, one can also get an estimate of the standard deviation of the responses in the domain. ${ }^{17,18}$ The responses near the boundaries will be very much different from the spatial average. These responses can be determined from the spatial average responses by using certain relations. ${ }^{19,20}$ For example, mean square response at the free end of a beam is four times the spatial average value of response. One can suitably design the structure for higher order modes by estimating the spatial average value of the response using SEA, their standard deviation and applying the relations for the response at the boundaries. While doing so, the subsystem is assumed have uniform structural properties. Elements like solar panels and antenna reflectors of spacecraft practically belong to this category, and this methodology is very much suitable as well as sufficient for their structural design in their higher order modes.

Many spacecraft panels do not have uniform structural property distribution. Several electronic instruments are mounted on the panels and the mass distribution is highly non-uniform. One such panel is shown in Fig. 1. Estimating the responses of such panels is very essential and very much crucial, especially for determining the random vibration loads for that equipment. The previous research ${ }^{3-14}$ determines the sound field generated due to vibration. In research where the vibration responses are determined, the structural panels are considered to have a uniform mass distribution. Though SEA is used in several applications, difficulties in estimating the response of structure with non-uniform structural properties limits its usage. Enabling the estimation of responses of panels with non-uniform mass distribution widens the application of SEA further. As the spatial average of response in such panels is meaningless, the most important feature needed is the ability to predict the responses at the required location, especially at the interface of the equipment.

Researchers have tried several methods to circumvent this limitation and thus to increase the applicability of SEA. One of them is the point impedance model developed by Clarkson et al. ${ }^{21}$ and another model is the AMA (Asymptotic Modal Analysis) model proposed by Kubota et.al. ${ }^{22}$ Both of these models are suitable for predicting the responses when the equipment can be considered as a point mass, that is the dimension of the equipment should be very small compared to the wavelength. One can see that these kinds of models are not suitable for predicting the response of an equipment panel shown in Fig. 1. Soize $^{23}$ proposed a methodology where a well-defined subsystem connected to a less well-defined subsystem is analyzed, but this is not practical when applied to the equipment panels. Renji et al. ${ }^{24}$ developed a methodology where the equipment is treated as a separate subsystem, represented by its mass as well as area. Responses are first estimated using SEA and the variation of response in the domain is determined from the interference pattern of bending waves generated in the panel. This was shown through studies done on a panel with one equipment attached. The results were also verified by conducting experiments.

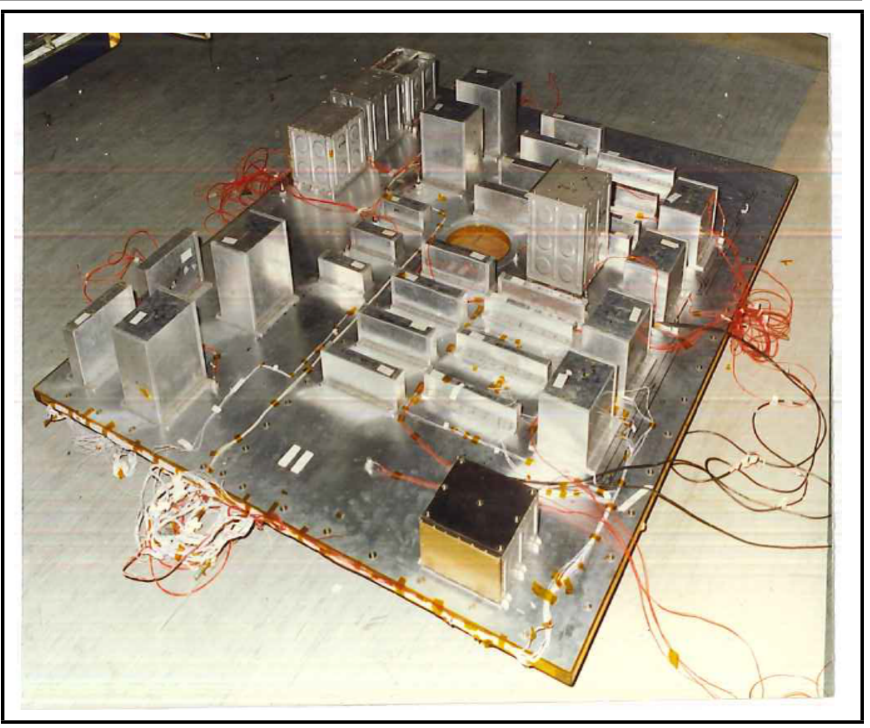

Figure 1. The photograph of the panel considered.

Another major development in this direction is to represent such subsystems by finite element models and the rest through SEA, called hybrid SEA model. This methodology was originally proposed by Langley and Bremner. ${ }^{25}$ Later several investigations on the theoretical aspects of the hybrid model, were carried out by many researchers ${ }^{26,27}$ especially on the coupling loss factors between subsystem represented by FEM and that represented by the SEA model. Hybrid SEA has become a very popular method, especially in the mid-frequency range. ${ }^{28,29}$ There are even commercial software packages incorporating hybrid SEA modeling and they are being used in determining responses in several applications. ${ }^{30}$

To determine the response of a panel having non-uniform mass distribution using hybrid SEA, one needs the finite element model of the panel. A typical spacecraft which is of a cubical shape has 6 faces comprised of panels with non-uniform mass distribution. The hybrid SEA needs finite element models of all the six panels which eventually becomes a finite element of model of the entire spacecraft. Even if one considers a single equipment panel, the finite element models of all the equipment are needed. Hybrid SEA becomes relevant when a few subsystems among several subsystems have to be represented by their finite element models.

Therefore, in the present work, the methodology developed by Renji et al. ${ }^{24}$ is pursued to apply it to an equipment panel where a large number of pieces of equipment are attached and the mass distribution is highly non-uniform. The panel is then subjected to a diffused acoustic field in a reverberation chamber and the responses are measured. The results are then compared to see where this methodology of prediction of response of such panels stands with respect to the measured results. It is to be noted that no results have been reported yet on such panels, neither on the prediction nor on the measured responses. The present work is a contribution in this direction. 


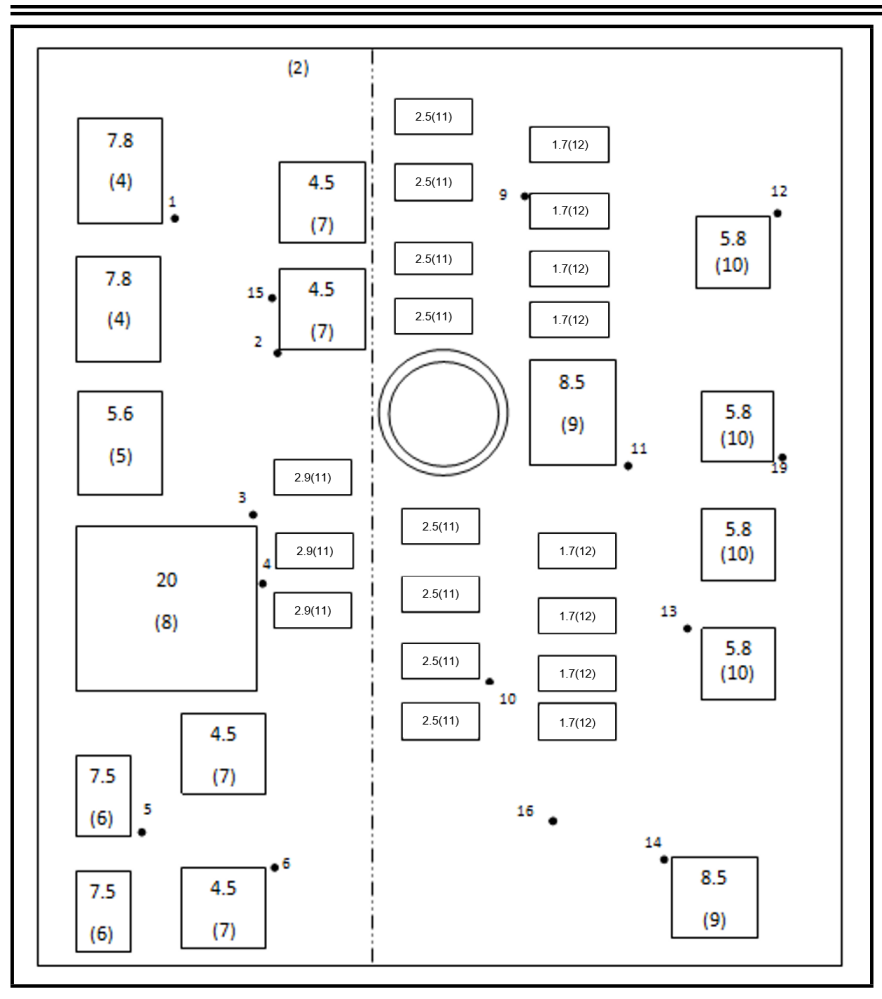

Figure 2. Schematic of the panel under study. - - Accelerometer location. () - SEA subsystem.

\section{DETAILS OF THE PANEL AND TEST SETUP}

The panel considered is a typical equipment panel of a spacecraft.

The panel is made of honeycomb sandwich construction. The thickness of the honeycomb core is $25.4 \mathrm{~mm}$. The panel is $2.3 \mathrm{~m}$ long and $1.93 \mathrm{~m}$ wide. Each face sheet has a thickness of $0.332 \mathrm{~mm}$ and is made of Aluminium alloy. Young's modulus of the material of the face sheet is $7.65 \times 10^{10} \mathrm{~N} / \mathrm{m}^{2}$, Poisson's ratio is considered to be 0.3 and the density is $2800 \mathrm{~kg} / \mathrm{m}^{3}$. The flexural rigidity of the panel, denoted by $D$, is calculated as $9240 \mathrm{Nm}$. The honeycomb core has a density of $32 \mathrm{~kg} / \mathrm{m}^{3}$. The shear modulus of the core is very low and the value provided by the manufacturer is $12.9 \times 10^{7} \mathrm{~N} / \mathrm{m}^{2}$.The shear rigidity of the panel, denoted by $N$, is calculated as $32.7 \times 10^{5} \mathrm{~N} / \mathrm{m}$. There are several heat pipes embedded in the panel. The measured mass of the bare panel is $26.6 \mathrm{~kg}$. There are a few concentrated masses, and $25.0 \mathrm{~kg}$ is the mass of the panel used for the determination of all SEA parameters.

A large number of pieces of equipment are mounted on the panel. A photograph is shown in Fig. 1. Figure 2 shows a sketch of the panel with the equipment shown as rectangles. The mass of each piece of equipment is shown within the rectangle. There are 35 pieces of equipment mounted on the panel. The total mass of the equipment mounted on the panel amount to $165 \mathrm{~kg}$. The mass of the panel with all the equipment is $191.6 \mathrm{~kg}$.

The panel is mounted on a test fixture. The test setup is shown in Fig. 3. To facilitate the mounting, four structural angles are fixed to the four sides of the fixture, one on each side. One side of each structural angle is bolted to the fixture at several locations. The panel is fixed on to the other side of the

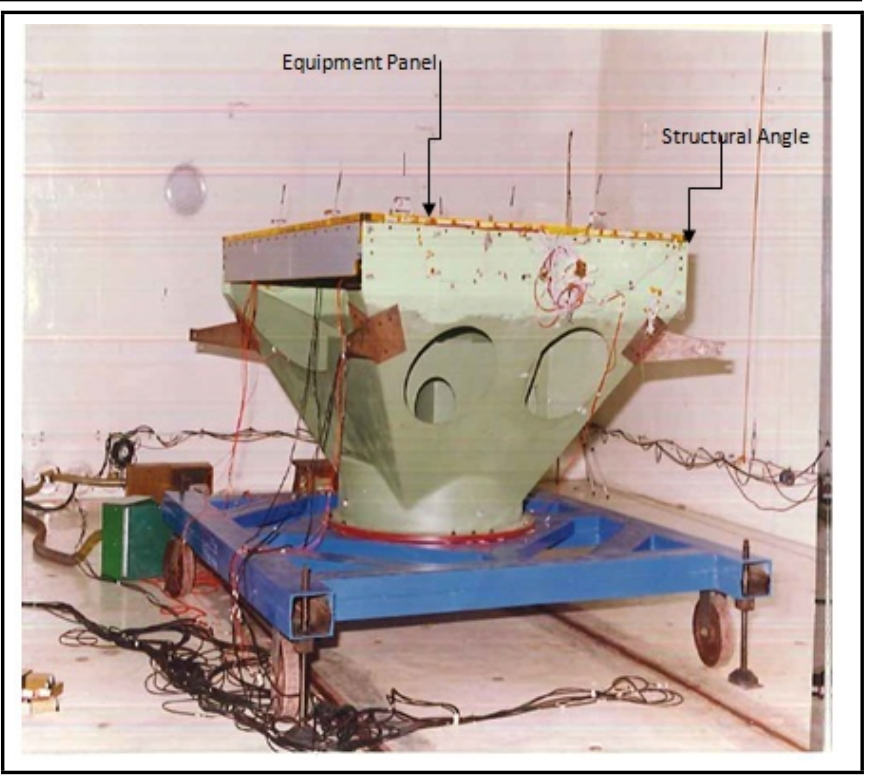

Figure 3. A photograph of the acoustic test setup.

structural angle, through inserts embedded in the panel. Thus the panel is supported at all four edges by structural angles. These supports act like simple supports as the angles are flexible and allow for rotation. In addition, the panel is also supported along the central line parallel to the longer edge ( $2.3 \mathrm{~m}$ long). This is done because, in spacecraft, large panels are supported additionally along such a line to a panel, called a shear panel. The shear panel is made of honeycomb sandwich construction and has dimensions of $2.3 \mathrm{~m} \times 0.54 \mathrm{~m}$ with $15 \mathrm{~mm}$ thick honeycomb. The equipment panel is bolted to the edge of the shear panel at several locations. The panel is mounted such that the face of the panel on which the equipment is mounted is towards the floor. Therefore, the equipment cannot be seen in Fig. 3.

A cone shaped structure is used to support the panel. The acoustic field is not reverberant near the floors and walls of the chamber. If the panel is kept very close to the floor, the sound field acting on the panel will be higher than the reverberant field. Beyond a distance of $1 \mathrm{~m}$, the field will be almost reverberant. The cone shaped structure keeps the panel at a distance of about $1.6 \mathrm{~m}$ from the floor of the reverberation chamber. The supporting structure should not have any enclosed cavity. If there is any enclosed cavity, standing waves will be developed in the cavity causing a significant sound field at certain specific frequencies. To overcome this problem, the cone shaped structure is provided with large sized cut-outs / openings.

\section{DETAILS OF THE TESTS AND TEST RESULTS}

The panel mounted on the test fixture was subjected to a diffused acoustic field in a reverberation chamber; the acceleration responses were measured at several locations.

The reverberation chamber has dimensions $10.33 \mathrm{~m} \times 8.2 \mathrm{~m}$ $\times 13.0 \mathrm{~m}$ (height). The volume of the chamber is $1101 \mathrm{~m}^{3}$ and the surface area is $651.2 \mathrm{~m}^{2}$. The medium of the chamber is air. When the experiment was conducted the temperature was 


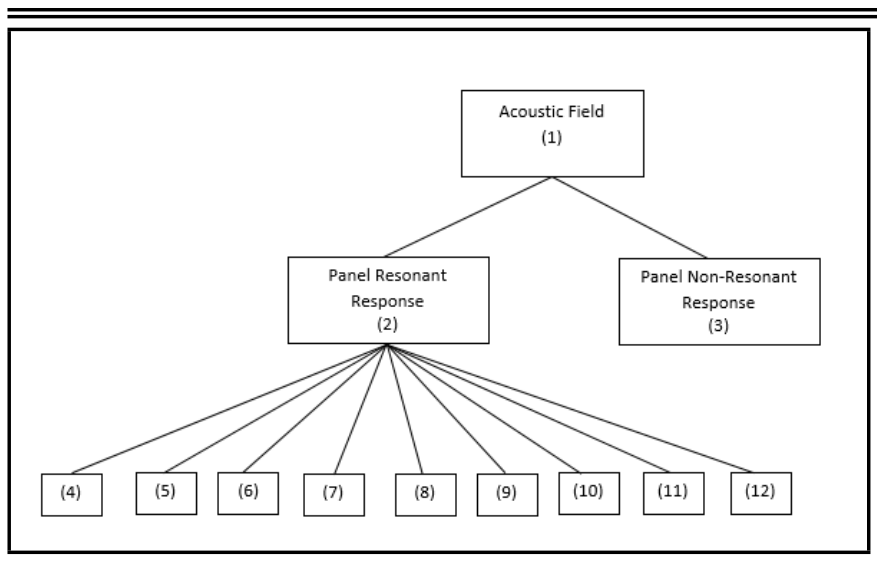

Figure 4. SEA model of the system.

$25^{\circ} \mathrm{C}$ and the relative humidity was $51 \%$. Correspondingly, the density of the air was $1.21 \mathrm{~kg} / \mathrm{m}^{3}$ and the speed of sound in the air is $346 \mathrm{~m} / \mathrm{s}$. All these parameters are required while computing the radiation resistance.

The fundamental acoustic mode of the chamber is $13.3 \mathrm{~Hz}$. In the third octave band centered at $63 \mathrm{~Hz}$ and above, the Sound Pressure Level (SPL) in the room is almost uniform. In the third octave band centered at $63 \mathrm{~Hz}$, there are 19 modes in the chamber. As this test deals with higher order modes, the results are presented from $315 \mathrm{~Hz}$ third octave band and above. In this frequency range, the sound field can be considered to be reverberant.

The SPL is measured at three locations using $1 / 4$ inch condenser microphones. The coordinates of the microphones are $M 1(2.15 \mathrm{~m}, 3.0 \mathrm{~m}, 3.0 \mathrm{~m}), M 2(-2.35 \mathrm{~m}, 3.0 \mathrm{~m}, 2.0 \mathrm{~m})$ and $M 3(2.3 \mathrm{~m},-3.5 \mathrm{~m}, 2.5 \mathrm{~m})$. The coordinate system is such that the origin is at the center of the floor and the $Z$ is the height from the floor. No correction factors need to be applied in the frequency range of interest. The spatial average of SPL at these three locations is taken as the excitation sound field. The time domain data is recorded and SPL is determined offline. They are presented in standard $1 / 3$ octave bands. Table 1 gives the sound field.

Accelerations were measured at 15 locations on the panel. They are shown in Fig. 2, with bold dots. Piezo-electric accelerometers were used for measurement. The accelerometers have useful frequency range $( \pm 5 \%)$ up to $5000 \mathrm{~Hz}$. The time domain data is recorded. Power Spectral Density (PSD) of the acceleration responses are obtained with a resolution of $5 \mathrm{~Hz}$. Root Mean Square (RMS) values in standard 1/3 octave bands were also obtained.

\section{DESCRIPTION OF THE SEA MODEL}

A model in SEA framework was developed. The SEA model had 12 subsystems. Figure 4 shows the SEA model of the system.

The sound field in the reverberation room is subsystem 1. The modal density of this subsystem can be computed using standard expressions available. ${ }^{1}$ The dissipation loss factor of the room is related to the absorption coefficient ${ }^{21}$ of the room which is a measured information. For completeness they are given here:

$$
n_{1}=4 \pi f^{2} V_{1} / c^{3}
$$

$$
\eta_{1}=S_{1} c \overline{\alpha_{1}} / 8 \pi f V_{1}
$$

where $n_{i}$ is the modal density and $\eta_{i}$ is the dissipation loss factor of $i_{t h}$ subsystem at frequency $f$. The room has a volume of $V$, surface area of $S$ and the absorption coefficient of the room is $\bar{\alpha}$ The speed of sound is denoted by $c$.

The portion of the panel where equipment is not mounted is called the subsystem "panel". The mass per unit area of the panel is $5.6 \mathrm{~kg} / \mathrm{m}^{2}$. The response of the "panel" consists of a resonant response and a non-resonant response. To determine them in SEA frame work, they are treated as two different subsystems. ${ }^{31}$ Subsystem 2 is the resonant response of the panel and subsystem 3 is the non-resonant response of the panel. The actual response of the panel will be the sum (mean square values of energies to be summed) of the responses of subsystems 2 and 3 . The dissipation loss factor considered is 0.05 for frequencies up to $1250 \mathrm{~Hz}$ and is 0.02 for frequencies above $1250 \mathrm{~Hz}^{24}$

The coupling loss factors involved in the resonant responses are the radiation resistance of the panel. The expressions derived originally by Maidanik, ${ }^{32}$ later modified by Crocker and Price $^{33}$ and Renji et. al. ${ }^{34}$ can be used in determining the radiation resistance. For brevity they are not reproduced here. The critical frequency of the subsystem panel is estimated as $526 \mathrm{~Hz}$ using the expression: ${ }^{35}$

$$
\omega_{c}^{2}=\left(c^{4} \rho / D\right) /\left\{1-\left(c^{2} \rho / N\right)\right\} .
$$

The modal density is estimated using the relation: ${ }^{36}$

$$
n(f)=\frac{\pi A \rho f}{N}\left\{1+\frac{\rho \omega^{2}+\frac{2 N^{2}}{D}}{\left(\rho^{2} \omega^{4}+\frac{4 \rho \omega^{2} N^{2}}{D}\right)^{1 / 2}}\right\} ;
$$

where $A$ is the area of the panel.

The coupling loss factors involved for the non-resonant response, if the subsystem has an area of $A_{i}$, mass per unit area of $\rho_{i}$ and a sound power transmission coefficient of $\tau_{i}$, are: ${ }^{31}$

$$
\begin{gathered}
\eta_{31}=\rho_{a} c / \rho_{3} \omega \\
\eta_{13}=2 \tau_{3} A_{3} c\left(1+\eta_{1} a\right) / 8 \pi f V_{1}
\end{gathered}
$$

where $\omega$ is the circular frequency in $\mathrm{rad} / \mathrm{s}$ and the parameter $a$ is equal to $\left(\rho \omega / 2 \rho_{a} c\right)$.

There are 35 equipment pieces mounted on the panel. As some of the equipment pieces are identical, they are combined and considered as one subsystem and the responses estimated for that subsystem are applicable for all those equipment pieces. All 35 equipment pieces can be grouped into nine types of equipment. In the SEA model, subsystems 4-12 represent these nine types of equipment. The SEA model is shown in Fig. 4. The SEA subsystem that represents each equipment is shown in Fig. 2, with SEA subsystem number given in brackets. As mentioned before, a few pieces of equipment which are more or less identical are represented by the same subsystem in the SEA model. Subsystem 12 represents eight equipment, each having a mass of $1.7 \mathrm{~kg}$. The equipment having a mass of $2.8 \mathrm{~kg}$ has a mass per unit area of $191 \mathrm{~kg} / \mathrm{m}^{2}$ and the mass per unit area of the equipment having a mass of $3.6 \mathrm{~kg}$ is $203 \mathrm{~kg} / \mathrm{m}^{2}$. As the mass per unit area of both types of equipment are very close and the length of the line junction of this 
Table 1. Response of the subsystem 'panel'.

\begin{tabular}{|c|c|c|c|}
\hline $1 / 3$ octave band centre frequency $(\mathrm{Hz})$ & SPL $(\mathrm{dB})$ & Estimated ( using Eq. (13)) RMS value of acceleration (g) & Measured RMS value of acceleration (g) \\
\hline 315 & 132.1 & 5.8 & 1.5 \\
\hline 400 & 123.9 & 2.7 & 1.2 \\
\hline 500 & 120.8 & 2.7 & 2.7 \\
\hline 630 & 119.3 & 1.2 & 0.9 \\
\hline 800 & 113.4 & 0.84 & 0.67 \\
\hline 1000 & 112.0 & 0.87 & 0.76 \\
\hline 1250 & 113.8 & 0.96 & 1.3 \\
\hline 1600 & 113.0 & 114.0 & 0.94 \\
\hline
\end{tabular}

equipment with the panel is also very close, both the pieces of equipment are combined and represented by the same SEA subsystem. Thus, SEA subsystem 11 represents 11 pieces of equipment. The dissipation loss factor considered is 0.05 .

The response of the equipment is due to the non-resonant response generated by the acoustic excitation, resonant response due to acoustic excitation and those due to the coupling with panel.

The non-resonant response of a plate having a random incidence sound power transmission coefficient of $\tau_{r}$ is given by: ${ }^{31}$

$$
<v^{2}>_{x}=\left(p_{r m s}^{2} / 4 \rho_{a}^{2} c^{2}\right) \tau_{r}
$$

The random incidence sound power transmission coefficient of a limp panel is

$$
\tau_{r}=8 \rho_{a}^{2} c^{2} / \rho^{2} \omega^{2}
$$

One can see that the non-resonant response is inversely proportional to the mass per unit area. Mass per unit area of the equipment varies between 120 to $220 \mathrm{~kg} / \mathrm{m}^{2}$, the least being $120 \mathrm{~kg} / \mathrm{m}^{2}$ compared to the mass per unit area of $5.6 \mathrm{~kg} / \mathrm{m}^{2}$ of the subsystem panel. The non-resonant responses of the subsystem equipment are expected to be quite negligible and hence they are not considered in the SEA model. Thus, there are 12 subsystems in the SEA model of the equipment panel.

The critical frequencies of subsystems 4-12 are quite high, much beyond the frequency of interest. As the radiation resistance at frequencies below critical frequency is very low, the radiation resistances of these subsystems are negligible. Therefore, the coupling loss factors between the acoustic field and subsystems 4-12 are not considered. The above reasoning leads to the result that the responses of this equipment are due to the coupling of these subsystems with the panel and not directly from the acoustic field.

The coupling loss factors between the panel and the equipment arise due to the change in the structural properties at their junctions. The applicable coupling loss factor between the panel (subsystem 2) and the equipment (subsystem 4) is given by: ${ }^{19}$

$$
\eta_{24}=2 c_{b, 2} L \tau_{24} /\left(\pi \omega A_{2}\right)
$$

where $c_{b}$ is the speed of the bending wave and $L$ is the length of the junction. The wave transmission coefficient $\tau_{24}$ can be determined using the relation: ${ }^{38}$

$$
\eta_{24}=\frac{2 \sqrt{\kappa \chi}(1+\kappa)(1+\chi)}{\kappa(1+\chi)^{2}+2 \chi(1+\kappa)^{2}} .
$$

The parameter $\kappa$ is the ratio of the speeds of the bending waves:

$$
\kappa=c_{b, 2} / c_{b, 4}
$$

and the parameter $\chi$ is given by:

$$
\chi=\left(c_{b, 2}^{2} / D_{2}\right) /\left(c_{b, 4}^{2} / D_{4}\right) .
$$

The wave attenuation is caused due to the change in the mass per unit area and flexural rigidity etc.

Since some of the pieces of equipment are combined and considered as one subsystem in the SEA model, the area and the mass of one piece of equipment is taken as the area and mass of the SEA subsystem. However, to satisfy the power balance, the length of the interface junction of the subsystem is the sum of the junction length of all such equipment. Even if all the identical pieces of equipment are treated as separate subsystems, the responses estimated for all those subsystems would be identical.

The SEA model thus developed is shown in Fig. 4.

\section{RESULTS AND DISCUSSION}

The acceleration responses were estimated using the SEA model described before and the results are presented here. These results were compared with the measured results to understand where we stand with respect to the theoretical predictions.

\subsection{Response of Panel}

The energy balance of the system gives the following relations between the energy of the subsystem, denoted by $E$, and the power input to the subsystem, $\pi$ :

$$
\omega\lfloor S Y S\rfloor\{E\}=\{\pi\} .
$$

As mentioned before, the SEA model has 12 subsystems and therefore $\lfloor S Y S\rfloor$ is a $12 \times 12$ matrix. The elements of this matrix are functions of the dissipation and the coupling loss factors. For the known input power, the energies of the subsystems can be determined by solving Eq. (13). Subsequently their acceleration responses were estimated.

The RMS values of acceleration responses of the subsystem "panel", thus determined are given in Table 1 and Fig. 5. The estimated results are the spatial average values, as in any SEA based prediction. They were compared with the measured spatial average results. Beyond $400 \mathrm{~Hz}$, the estimated results were in good agreement with the measured results. Differences seen at low frequencies, which is expected in an SEA based estimation, were due to fewer number of modes being present in these bands. 


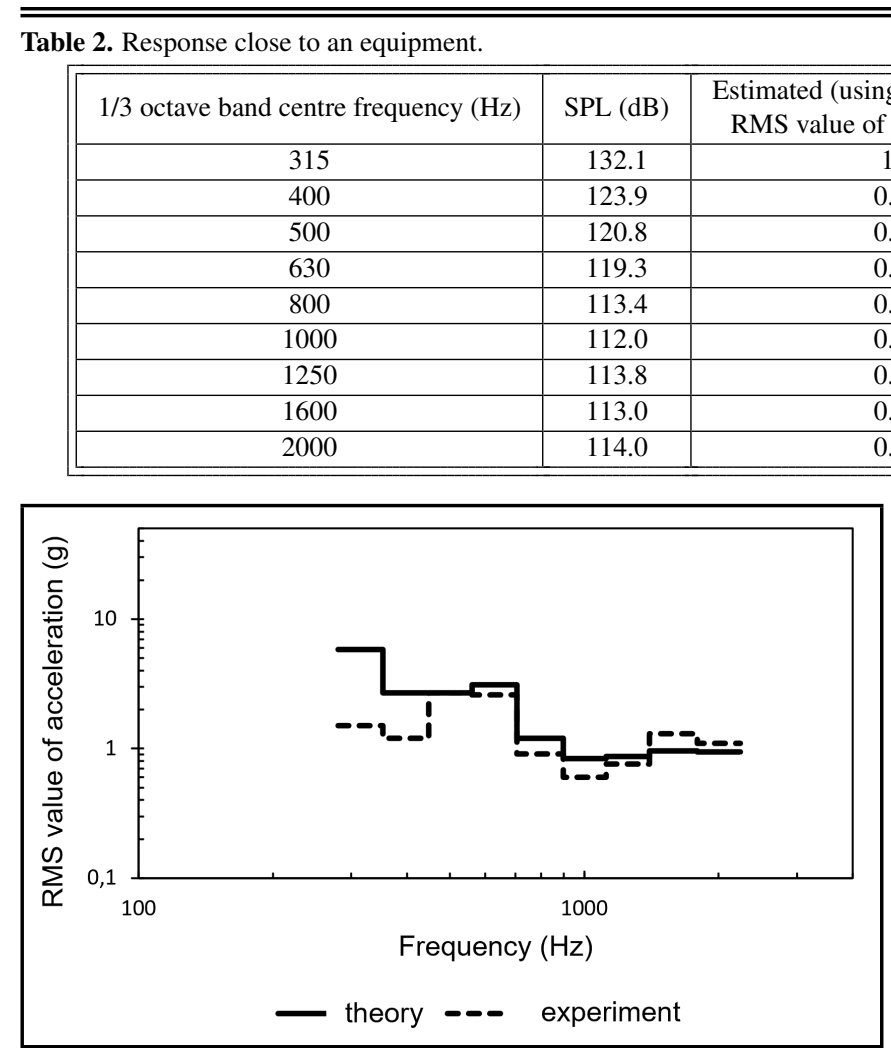

Figure 5. RMS value of acceleration response (using Eq. (13)) of 'panel'.

\subsection{Response at the Interface of the Equipment}

In practice, the response at the interface of the equipment is desired. The response at the location which is at a distance $x$ from an equipment is determined using the methodology described in: ${ }^{24}$

$$
\begin{aligned}
& <v^{2}>=\frac{B^{2}}{2}\left[\left\{(1+G) \cos k x-H \sin k x+P e^{k x}\right\}^{2}\right. \\
& \left.+\left\{(1-G) \sin k x-H \cos k x+Q e^{k x}\right\}^{2}\right]
\end{aligned}
$$

where $G$ and $P$ are the real parts and $H$ and $Q$ are the imaginary parts of the far field and near field reflection coefficients as defined by Heckl ${ }^{38}$ and:

$$
B^{2}=2<v^{2}>_{x} /\left\{1+G^{2}+H^{2}\right\}
$$

where $\left\langle v^{2}>_{x}\right.$ is the spatial average value of the response which can be determined using SEA. Thus, response at any location can be estimated using Eq. (14) along with Eq. (15).

Using the SEA model described before, the spatial average values of acceleration responses of all equipment were determined. The responses were measured at several locations on the panel and at the interfaces of several equipment. The results are presented here for a particular type of equipment which has a mass of $4.5 \mathrm{~kg}$ and having interface dimensions $215 \mathrm{~mm} \times 185 \mathrm{~mm}$. This equipment was represented by subsystem 7 in the SEA model. The response was measured at location 2 which is shown in Fig. 2. The estimated and measured responses at location 2 are given in Table 2 and Fig. 6. One can see a reasonably good agreement in the mid-frequency range and at higher frequencies the measured responses being higher.

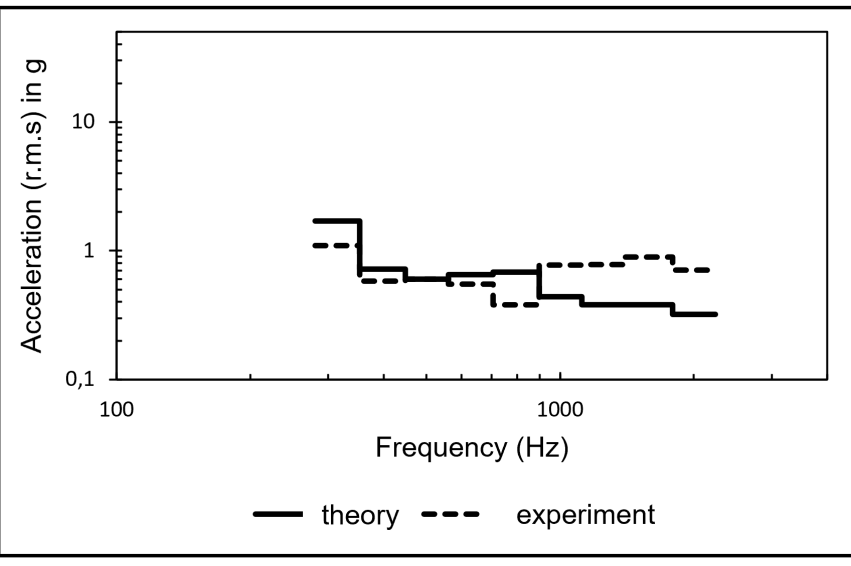

Figure 6. RMS value of acceleration response (using Eqs. (13), (14)) close to an equipment.

\subsection{PSD of Response}

For specifying random vibration loads for equipment, one needs to estimate the Power Spectral Density (PSD) of the acceleration response. One can determine the PSD by dividing the mean square value by the band width. However, the PSD thus determined will be an average value and hence it gives a very low value compared to the measured. Therefore, the methodology presented in reference ${ }^{39}$ is attempted here. If the mean square value of acceleration in the given band is $\left\langle a^{2}>\right.$, PSD of acceleration response, denoted by $\phi_{a a}(f)$, is given by:

$$
\phi_{a a}(f)=\frac{<a^{2}>}{(\delta N)(\pi / 2) \Delta} ;
$$

where $\delta N$ is the number of modes present in the band and $\Delta$ is the half-power bandwidth of a mode. The estimated PSD of the acceleration response is given in Table 2. The PSD of the measured acceleration response at location 2 is shown in Fig. 7.

In $315 \mathrm{~Hz}$ band, the estimated response is $0.035 \mathrm{~g}^{2} / \mathrm{Hz}$ whereas the measured value is approximately $0.03 \mathrm{~g}^{2} / \mathrm{Hz}$.

It is thus demonstrated that the responses of such panels can be determined in SEA framework. As a side-note, if the response of this panel at location 2 is extrapolated for the acoustic levels to which the spacecraft needs to be designed and tested, the estimated response in $315 \mathrm{~Hz}$ band will be $0.15 \mathrm{~g}^{2} / \mathrm{Hz}$. This type of equipment is generally tested to a PSD of random vibration of $0.22 \mathrm{~g}^{2} / \mathrm{Hz}$ in the above band. It is to be noted that what is attempted here is estimation of the PSD of acceleration response of a panel with large number of equipment attached, in SEA framework. 


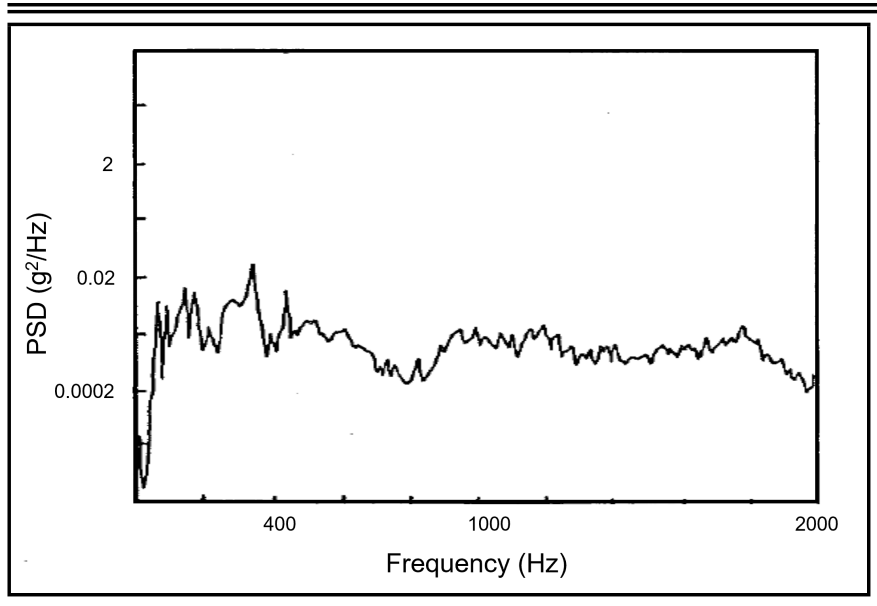

Figure 7. PSD of measured acceleration response, close to the equipment.

\section{CONCLUSIONS}

A methodology in SEA framework was developed to estimate the responses for panels with non-uniform mass distribution. The pieces of equipment were considered as separate subsystems and the SEA model was built. The acceleration responses of the equipment were estimated using the SEA model, which is a spatial average. The accelerations at the interface of the equipment were then determined based on the standing waves generated due to the change in the structural properties. Following this methodology, the acceleration responses of a typical equipment panel mounted with several equipment pieces were estimated. They are in good agreement with the experimentally obtained results. The application of SEA in situations where the mass distribution was not uniform, was thus demonstrated. The response of the equipment is mainly through the line connection with the panel and the response generated directly from the acoustic filed was negligible.

\section{ACKNOWLEDGEMENTS}

Author acknowledges the support rendered by the staff of Acoustic Test Facility, National Aerospace Laboratories, Bangalore in conducting the experiments. Critical discussions with Dr. P.S Nair, earlier Group Director, Structures Group are well remembered.

\section{REFERENCES}

1 Lyon RH, Statistical Energy Analysis of Dynamical Systems: Theory and Applications, MIT Press, Cambridge, MA, (1975).

2 Keane, A.J. and Price, W.G. Statistical energy analysis: an overview with applications to structural dynamics, Cambridge University Press, Cambridge, UK, (1997).

3 Clarkson, B.L., Cummins, R.J., Eaton, D.C.G. and Vessaz J.P. Prediction of high frequency structural vibrations using Statistical Energy Analysis (SEA), ESA Journal, 5, 535-549 (1981).
4 Salzberg, A.A. Validation of LACE spacecraft vibroacoustic prediction model, Journal of Environmental Sciences, 32, 53-59, (1989).

5 Miller, V.R. and Faulkner L.L. Prediction of aircraft interior noise using the statistical energy analysis method, Transactions of the ASME, Journal of Vibration and Acoustics, Stress and Reliability in Design, 105(4), 512-518, (1983). https://dx.doi.org/10.1115/1.3269136

6 Borello, G. Vibrational Energy prediction of the response of the VULCAIN rocket engine using a mixed FET/SEA analysis, Proceedings of INTERNOISE 92, Canada, 553556, (1992).

7 Walsh, S.J., Stimpson, G. and Lalor, N. A computer system to predict internal noise in motor cars using statistical energy analysis, Proceedings of INTERNOISE 90, Sweden, 969-972, (1990).

8 Stimpson, G. and Lalor, N. SEA extension of a FE model to predict total engine noise, Proceedings of INTERNOISE 92, Canada, 557-560, (1992).

9 Júlio A. Cordioli, Mário Trichês Jr. and Samir N. Y. Gerges. Applications of the Statistical Energy Analysis to vibroacoustic modeling of vehicles, SAE conference (2004). https://dx.doi.org/10.4271/2004-01-3352

10 Hynna, P., Klinge, P. and Vuoksinen, J. Prediction of structure-borne sound transmission in large welded ship structures using statistical energy analysis, Journal of Vibration and Acoustics, 180(4), 583-607, (1995). https://dx.doi.org/10.1006/jsvi.1995.0101

11 Craik, R.J.M. The prediction of sound transmission through buildings using statistical energy analysis, Journal of Vibration and Acoustics, 82(4), 505-516, (1982). https://dx.doi.org/10.1016/0022-460X(82)90404-7

12 Wilson, R. and Craik, R.J.M. Sound transmission through dry lined walls, Journal of Vibration and Acoustics, 192(2), 563-579, (1996). https://dx.doi.org/10.1006/jsvi.1996.0204

13 Jens Forssen, Stefan Tober, Ata Can Corakci, Anders Frid and Wolfgang Kropp. Modelling the interior sound field of a railway vehicle using statistical energy analysis, Applied Acoustics, 73(4), 307-311, (2012). https://dx.doi.org/10.1016/j.apacoust.2011.09.012

14 Bill Dawson, Neil Mackenzie and Yong Keat Lee. Applications of statistical energy analysis to rail noise predictions, Proceedings of ACOUSTICS 2017, Perth, Australia, 1-10 (2017).

15 Fahy, F.J. Statistical energy analysis: a critical overview, Philosophical Transaction of Royal society of London, 346(5), 431-447 (1994). https://dx.doi.org/10.1098/rsta.1994.0027 
16 Fahy, F.J. and Price, W.G. IUTAM symposium on Statistical Energy Analysis, Springer, Southampton (1999).

17 Stearn, S.M. Spatial variation of stress, strain and acceleration in structures subject to broad frequency band excitation, Journal of Vibration and Acoustics, 12(1), 85-97, (1970). https://dx.doi.org/10.1016/0022-460X(70)90049-0

18 Stearn, S.M. The concentration of dynamic stress in a plate at a sharp change of section, Journal of Vibration and Acoustics, 15(3), 353-365, (1971). https://dx.doi.org/10.1016/0022-460X(71)90429-9

19 Lyon, R.H. and De Jong, R.G. Theory and applications of Statistical Energy Analysis, Buttrworth-Heinermann, USA (1995).

20 Langeley, R.S. Response variance prediction in the statistical energy analysis of built-up systems, Journal of the Acoustical Society of America, 115(2), 231-234, (2004). https://dx.doi.org/10.1121/1.1642621

21 Clarkson, B.L., Pope, R.J. and Ranky, M.F. Study of the Evolution of Structural Acoustic Design Guides, ESA CR(P) 1609, Vol. 2, (1981).

22 Kubota, Y., Sekimoto, S. and Dowell, E.H. The high frequency response of a plate carrying a concentrated mass, Journal of Vibration and Acoustics, 138(2), 321-333, (1990). https://dx.doi.org/10.1016/0022-460X(90)90545-B

23 Soize, C. A model and numerical method in the medium frequency range for vibro-acoustic prediction using the theory of structural fuzzy, Journal of the Acoustical Society of America, 94, 849-865 (1993). https://dx.doi.org/10.1121/1.408186

24 Renji, K., Nair, P.S. and Narayanan, S. Acoustic response behaviour of panels mounted with equipment and its prediction using statistical energy analysis, Journal of Vibration and Acoustics, 289(4-5), 851-870, (2006). https://dx.doi.org/10.1016/j.jsv.2005.02.041

25 Langley, R.S. and Bremner, P. A hybrid method for the vibration analysis of complex structural-acoustic systems, Journal of the Acoustical Society of America, 105(3), 1657-1671 (1999). https://dx.doi.org/10.1121/1.426705

26 Langley, R.S. and Shorter, P.J. The wave transmission coefficients and coupling loss factors of point connected structures, Journal of the Acoustical Society of America, 113(4), 1947-1964 (2003). https://dx.doi.org/10.1121/1.1515791

27 Ji, L., Mace, B.R. and Pinnington, R.J. A mode-based approach for the mid-frequency vibration analysis of coupled long- and short-wavelength structures, Journal of Vibration and Acoustics, 289(1-2), 148-170 (2006). https://dx.doi.org/10.1016/j.jsv.2005.02.003
28 Langley, R.S. Shorter, P.J., Lande, R.H. and Cotoni, V. Hybrid deterministic-statistical modeling of built-up structures, Proceedings of ICSV12 Conference, Lisbon, Portugal, July 11-14 (2005).

29 Cotoni, V. and Shorter, P. Numerical and experimental validation of a hybrid finite element-statistical energy analysis method, Journal of the Acoustical Society of America, 122(1), 259-270 (2007). https://dx.doi.org/10.1121/1.2739420

30 Annu Cherian, Geena George, P. and Prabha, C. Response analysis of payload fairing due to acoustic excitation, Int. J. of Scientific and Technology Research, 4(11), 302-305, (2015).

31 Renji, K., Nair, P.S. and Narayanan, S. Non-resonant response using statistical energy analysis, Journal of Sound and Vibration, 241(2), 253-270, (2001). https://dx.doi.org/10.1006/jsvi.2000.3270

32 Maidanik, G. Response of ribbed panels to reverberant acoustic fields, Journal of the Acoustical Society of America, 34(6), 809-826, (1962). https://dx.doi.org/10.1121/1.1918200

33 Crocker, M.J. and Price, A.J. Sound transmission using statistical energy analysis, Journal of Sound and Vibration, 9(3), 469-486 (1969). https://dx.doi.org/10.1016/0022$460 X(69) 90185-0$

34 Renji, K.,Nair, P.S. and Narayanan, S. On acoustic radiation resistance of plates, Journal of Sound and Vibration, 212(4), 583-598, (1998). https://dx.doi.org/10.1006/jsvi.1997.1438

35 Renji, K., Nair, P.S. and Narayanan, S. Critical and coincidence frequencies of flat panels, Journal of Sound and Vibration, 205(1), 19-32, (1997). https://dx.doi.org/10.1006/jsvi.1997.0992

36 Clarkson, B.L. and Ranky, M.F., Modal density of honeycomb plates, Journal of Sound and Vibration, 91(1), 103-118, (1983). https://dx.doi.org/10.1016/0022$460 x(83) 90454-6$

37 Renji, K. Modal density and critical frequency of composite panels considering transverse shear deformation and rotary inertia, Journal of Vibration and Control, 26(17-18), 1503-1513, (2020). https://dx.doi.org/10.1177/1077546319898980

38 Cremer, L., Heckl, M. and Ungar, E.E. Structure-borne sound, Springer Verlag, New York (1973).

39 Renji, K. Estimation of spectral density using statistical energy analysis, Journal of Sound and Vibration, 275(1), 447451, (2004). https://dx.doi.org/10.1016/j.jsv.2003.10.007 